\title{
Inventário de Características Psicológicas Associadas ao Desempenho Académico: Validação em Alunos Universitários
}

\author{
Ana Pereira Antunes ${ }^{1}$ \\ Universidade da Madeira, Funchal, Portugal \\ Maria de Fátima Morais \\ Universidade do Minho, Braga, Portugal \\ Fernanda Martins \\ Universidade do Porto, Porto, Portugal
}

\section{RESUMO}

Este estudo teve como objetivo adaptar e validar à população portuguesa um questionário de autorrelato para estudar alunos de mérito acadêmico, desenvolvido, originalmente, por investigadores holandeses, designado na versão portuguesa por Inventário de Características Psicológicas Associadas ao Desempenho Acadêmico. Participaram 1366 alunos (771 mulheres e 597 homens) do $1^{\circ}$ ciclo do ensino superior português de cursos pertencentes a três áreas do conhecimento: Ciências e Tecnologias, Ciências Sociais e Humanas, Artes e Humanidades. A análise fatorial exploratória apontou para uma estrutura com seis fatores relacionados com as dimensões: Cognitivo-Criativa; Motivação e Estratégias de Aprendizagem, Persistência, Interação Social, Procura de Excelência e Interesse Cultural. Os índices de fidelidade (alfa de Cronbach) para cada uma dessas dimensões revelam-se adequados. Os resultados são discutidos e são apresentadas linhas orientadoras para estudos futuros.

Palavras-chave: rendimento escolar; avaliação psicológica; ensino superior.

\section{ABSTRACT - Inventory of Psychological Characteristics Associated with Academic Performance: University Students Validation}

This study aimed to adapt and validate a self-report questionnaire to study students of academic merit for a Portuguese population. The Inventory of Psychological Characteristics Associated with Academic Performance was originally developed by Dutch researchers. The sample consisted of 1,366 students (771 women, $597 \mathrm{men}$ ) from the 1st cycle degree in the Portuguese higher education, belonging to three areas of study: Science and Technology, Social and Human Sciences, and Arts and Humanities. Exploratory factor analysis pointed to a six-factor structure related to three dimensions: Cognitive-Creative, Motivation and Learning Strategies, Persistence, Social Interaction, Search for Excellence, and Cultural Interest. Reliability indexes (Cronbach's alpha) for each of these dimensions are adequate. The results are discussed and guidelines are presented for future studies.

Keywords: academic achievement; psychological evaluation; higher education.

\section{RESUMEN - Inventario de Características Psicológicas Asociadas con el Desempeño Académico: Validación en Estudiantes Universitarios}

Este estudio tuvo como objetivo adaptar y validar en la población portuguesa un cuestionario de autoinforme para estudiar alumnos de mérito académico, desarrollado originalmente por investigadores holandeses; la versión portuguesa se denomina Inventario de Características Psicológicas Associadas ao Desempenho Académico (Inventario de Características Psicológicas Asociadas al Desempeño Académico). Participaron 1366 estudiantes (771 mujeres y 597 hombres) de primer ciclo de enseñanza universitaria portuguesa de cursos pertenecientes a tres áreas del conocimiento: Ciencia y Tecnología, Ciencias Sociales y Humanas, Arte y Humanidades. El análisis factorial exploratorio señaló una estructura con 6 factores relacionados con las dimensiones: Cognitivo-creativa; Motivación y Estrategias de Aprendizaje; Persistencia; Interacción Social; Búsqueda de Excelencia e Interés Cultural. Los índices de fidelidad (alfa de Cronbach) para cada una de estas dimensiones se mostraron adecuados. Los resultados son discutidos y se presentan líneas directrices para futuros estudios.

Palabras clave: rendimiento escolar; evaluación psicológica; enseñanza universitaria.

A investigação sobre alunos com altas habilidades acontece, em Portugal, de forma mais intensiva nos últimos anos, mas esse tópico tem captado menor atenção no ensino superior. No entanto, revela-se uma área de investigação emergente com alguns estudos (Antunes \& Morais, 2015), sendo que a literatura internacional ainda 
aponta para a necessidade de mais estudos sobre essa população (McLaughlin, 2015; Rinn, 2005).

De uma forma geral, reconhece-se o desempenho excelente numa dada área como correspondendo à manifestação de um talento que, "por definição, é uma expressão visível do alto grau de capacidade interna do indivíduo, pelo desempenho extraordinário em alguma via de ação diferenciada no ambiente físico-sóciocultural" (Gunther, 2015, p.10). No caso deste trabalho, interessa sobremaneira a excelência acadêmica. Mais concretamente, interessa a possibilidade de reconhecimento e de caracterização dos alunos de alto rendimento, no ensino superior, sendo necessário maior conhecimento sobre as idiossincrasias deles, os quais têm sido designados como, por exemplo, alunos de mérito acadêmico, de excelência ou com altas capacidades.

A definição de um aluno de mérito não é tarefa fácil, registando-se investigação que considera tais alunos como um grupo tendencialmente homogêneo, enquanto outros estudos apontam maior heterogeneidade entre esses alunos (Rinn, 2005). Todavia, considerando a diversidade que pode caracterizá-los, existem, de forma geral, aspetos comuns, tais como o rendimento acadêmico elevado, a motivação e a curiosidade, o interesse elevado e dirigido a diferentes temáticas, e grande entusiasmo pelo conhecimento (Achterberg, 2005).

A criatividade aparece também cada vez mais associada à produção excecional e inovadora, permitindo diferenciar o sucesso profissional dos alunos talentosos (Kim, 2009) em qualquer área de conhecimento (Morais, 2013). Dessa forma, o modelo de Renzulli (2005), modelo dos três anéis, para a explicação do comportamento sobredotado, pressupõe que o mesmo aconteça quando existe a interseção de elevado compromisso com a tarefa (motivação), com alta habilidade e criatividade. Posteriormente, reconhecendo a importância do contexto e da personalidade na produção excecional, Renzulli (2005) propõe uma evolução do modelo dos três anéis para o que designou Operação Houndstooth, introduzindo uma dimensão caracterizada por seis fatores cocognitivos, compostos por subcomponentes, ou seja, otimismo, coragem, paixão por um tema ou disciplina, sensibilidade às temáticas humanas, energia física/mental, visão/sentido de destino. Nesse novo modelo, onde a interação dos fatores pode conduzir à sabedoria e à satisfação com a vida, o autor enfatiza a noção de capital social e como as pessoas com altas habilidades podem contribuir com as suas produções para o bem comum por meio do desenvolvimento não só científico e tecnológico, mas também humano e social (Renzulli, 2005).

Contudo, a identificação e caracterização dos alunos capazes de excelência acadêmica, mesmo em níveis educativos básicos, revela dificuldades, sobretudo quando se alarga a avaliação a aspetos psicológicos além da capacidade intelectual. Aliás, o desempenho excelente também aparece associado a diversas variáveis psicológicas, desde fatores intelectuais e cognitivos a fatores de motivação e de personalidade (Almeida \& Wechsler, 2015). A aprendizagem requer mais do que conhecimento prévio e habilidades cognitivas porque a aprendizagem nunca é apenas atividade racional, depende também de fatores afetivos e motivacionais (Lohman, 2009).

Inerente à avaliação psicológica, e associada à importância de considerar componentes cognitivas e de personalidade, é reconhecida a necessidade de diferentes fontes de informação, mas a forma de combiná-las e de extrair conclusões ainda pode ser dúbia (Lohman, 2009). Lohman (2009) refere que, por um lado, pode ser adequado recolher informação junto dos professores, por meio de escalas de motivação, de criatividade e de competências de comunicação, mas, por outro lado, a forma de combinar essa informação com outros dados sobre os interesses, as habilidades e os desempenhos dos alunos, parece revelar-se mais como engenho e arte do que propriamente ciência.

Nesse sentido, Renzulli (2005), baseado no modelo dos três anéis anteriormente citado, propõe um modelo de identificação, sendo que os procedimentos a adotar na identificação dos alunos não se distinguem dos utilizados na fase inicial das abordagens mais tradicionais, isto é, a sinalização, contemplando-se genericamente os desempenhos em testes de aptidão e inteligência, a nomeação pelos pais, pelos professores e pelos alunos, bem como os produtos criativos. No entanto, a forma de combinar os resultados dessas diferentes fontes tem suscitado algumas questões, pois não está claramente explicitada pelo autor, sendo que em diferentes etapas do desenvolvimento do aluno se podem equacionar diferentes fatores diferenciadores. Por exemplo, à medida que se avança na escolaridade, a associação entre o desempenho escolar e as aptidões cognitivas vai decrescendo (Antunes \& Almeida, 2010). Procurando perceber o que favorece a realização acadêmica excelente no ensino superior, têm surgido alguns estudos com recurso a metodologia qualitativa (e. g., Monteiro, Almeida, Rosa, \& Cruz, 2014), procurando explorar variáveis mais processuais e mais dificilmente mensuráveis, e outros estudos de natureza mais quantitativa (e. g., Scager et al. 2012), procurando explorar a associação de variáveis ao desempenho excelente. Mas, apesar dos esforços para a avaliação psicológica dos alunos com altas capacidades intelectuais e acadêmicas, a questão da sua caracterização ainda continua em aberto, parecendo que a investigação existente ainda se revela insuficiente para que se possam traçar conclusões definitivas acerca das características dos alunos de mérito no ensino superior (Rinn, 2005).

Perante este fato, surge o trabalho realizado por um grupo de investigadores holandeses (Scager et al., 2012), partindo do modelo teórico de sobredotação de Renzulli (2005), já referido anteriormente, dada a ausência de um instrumento único que permita avaliar as três componentes do modelo, ou seja, a convergência 
da presença, em níveis elevados, de motivação, inteligência e criatividade. Assim, com itens formulados a partir desses três construtos teóricos, foi desenvolvido um questionário de autorrelato, inicialmente constituído por 68 itens e apresentando, na versão final, 31 itens (Scager et al., 2012). Nessa versão, o questionário organiza-se em seis escalas: Inteligência, Pensamento Criativo, Abertura à Experiência, Desejo de Aprender, Orientação para a Excelência e Persistência, e permite diferenciar as perceções de alunos de mérito acadêmico dos outros alunos (Scager et al., 2012). Mais recentemente, dada a ausência de uma versão portuguesa, ou de outro instrumento que permita recolha de informação similar, foi desenvolvido um estudo (Antunes, Morais, \& Martins, 2015), partindo da versão original holandesa (Scager et al., 2012), que revelou qualidades psicométricas promissoras e permitiu a diferenciação de grupos de alunos em função do desempenho acadêmico. Nessa versão portuguesa, assumiu-se a designação de Inventário de Características Psicológicas Associadas ao Desempenho Acadêmico (ICPADA), e organizou-se em seis escalas com um total de 54 itens: CognitivoCriativa, Motivação e Estratégias de Aprendizagem, Persistência, Interação Social, Procura de Excelência, e Interesse Cultural.

Considerando a revisão da literatura apresentada, o principal objetivo deste trabalho prende-se com a adaptação e validação a alunos universitários portugueses do questionário originalmente trabalhado por Scager et al. (2012), aqui designado por ICPADA.

\section{Método}

\section{Participantes}

Participaram no estudo 1366 alunos do $1^{\circ}$ ciclo do ensino superior de três universidades portuguesas (duas públicas e uma privada), sendo 771 mulheres (56,4\%) e 597 homens $(43,6 \%)$, com uma idade média de 21,32 anos $(D P=4,43)$, oscilando entre 17 e 62 anos. Os participantes pertencem a cursos de três áreas do conhecimento: Ciências e Tecnologias, com 515 (37,7\%) alunos; Ciências Sociais e Humanas, com 500 (36,6\%) alunos; Artes e Humanidades, com 351 (25,7\%) alunos. No $1^{\circ}$ ciclo, havia $525(38,4 \%)$ alunos no $1^{\circ}$ ano, $473(34,6 \%)$ no $2^{\circ}$ ano e $357(26,1 \%)$ no $3^{\circ}$ ano. Havia ainda um pequeno grupo matriculados no $2^{\circ}$ ciclo, mas a frequentarem disciplinas do $1^{\circ}$ ciclo, composto por 10 alunos $(0,7 \%)$ no $4^{\circ}$ ano e 1 aluno $(0,1 \%)$ no $5^{\circ}$ ano.

\section{Instrumentos}

Aplicou-se um questionário de autorrelato desenvolvido por investigadores holandeses (Scager et al., 2012), tendo, como suporte essencial, o modelo dos três anéis sobredotação de Renzulli (2005). Os autores listaram uma série de itens, que poderão traduzir características associadas quer a um compromisso e empenho elevado com a tarefa (motivação) quer a habilidades cognitivas e criativas acima da média (Scager et al., 2012).

A versão original do questionário continha 68 itens, sendo que a versão final apresentou 31 itens, agrupados em seis escalas (Scager et al., 2012b): Inteligência (seis itens e $\alpha=0,71$ ), Pensamento Criativo (seis itens e $\alpha=0,76$ ), Abertura à Experiência (quatro itens e $\alpha=0,70$ ), Desejo de Aprender (seis itens e $\alpha=0,78$ ), Orientação para a Excelência (três itens e $\alpha=0,83$ ) e Persistência (seis itens e $\alpha=0,73$ ), as quais permitiram a recolha de informação sobre dimensões associadas ao elevado desempenho acadêmico e encontrar diferenciação entre os resultados dos alunos excelentes e os dos alunos restantes (Scager et al., 2012).

Nessa investigação, foi aplicada a versão original do questionário com 68 itens, tendo sido traduzidos e avaliados por dois juízes independentes quanto à clarificação da linguagem (tradução e retroversão). O questionário foi designado Inventário de Características Psicológicas Associadas ao Desempenho Acadêmico (ICPADA).

Quanto às respostas, seguiu-se igualmente a opção da versão original, sendo assinaladas, para cada item, numa escala tipo Likert de 7 pontos, oscilando entre 1 (nada verdadeira para mim) e 7 (muito verdadeira para mim). Foi também construída e testada uma versão do inventário on-line.

\section{Procedimentos}

O estudo realizou-se após pedido de autorização e contacto com os docentes, permitindo agendar a aplicação do ICPADA, que foi realizada pela primeira autora deste artigo e decorreu em contexto de sala de aula. Os questionários foram distribuídos pelos alunos que manifestaram disponibilidade em participar, sendo preenchidos individualmente e recolhidos à medida que o preenchimento acontecia, apesar de se ter criado e testado uma versão on-line, que não se utilizou dada a baixa adesão registada. Posteriormente, os dados foram informatizados, recodificando-se os itens formulados em sentido inverso, e analisados com o programa $I B M$ SPSS Statistics, versão 23.

Essa investigação insere-se num projeto de pós-doutoramento aprovado pelo Conselho Científico do Instituto de Educação da Universidade do Minho (Portugal), estando também inserido no Centro de Investigação em Educação (CIEd), regulando-se consequentemente pelos princípios éticos defendidos nesses contextos. A utilização do questionário foi devidamente autorizada pelos seus autores e a sua aplicação foi realizada mediante consentimento informado dos professores e alunos.

\section{Resultados}

Apresentam-se os resultados obtidos por meio de uma análise fatorial exploratória $(\mathrm{KMO}=0,939$, $\left.\chi^{2}=31408,979, g l=2278 ; p<0,001\right)$, sendo a extração dos 
itens efetuada pela análise dos Quadrados Mínimos não Ponderados (Unweighted Least Squares, ULS) com rotação Varimax. Considerando a aceitação dos itens com carga fatorial igual ou superior a 0,35 e tendo em consideração que o questionário original se organizava em seis escalas, resultou uma estrutura fatorial de seis fatores, os quais explicam 41,69\% da variância, conforme se apresenta em detalhe na Tabela 1 . Todos os fatores têm valor-próprio superior a 1, aparecendo o fator I com a maior carga fatorial, justificando $22,03 \%$ da variância.

Tabela 1

Estrutura Fatorial dos Itens do ICPADA

\begin{tabular}{|c|c|c|c|c|c|c|c|}
\hline \multirow{2}{*}{ Itens } & \multicolumn{7}{|c|}{ Fatores } \\
\hline & I & II & III & IV & $\mathrm{V}$ & VI & $h^{2}$ \\
\hline 39. Sou capaz de compreender novas ideias com facilidade. & 0,69 & & & & & & 0,59 \\
\hline $\begin{array}{l}\text { 37. Sou muitas vezes capaz de perceber o panorama geral, enquanto } \\
\text { os outros não o conseguem fazer. }\end{array}$ & 0,66 & & & & & & 0,48 \\
\hline $\begin{array}{l}\text { 21. Tenho uma capacidade para descobrir o potencial de ideias que } \\
\text { os outros geralmente não conseguem ver. }\end{array}$ & 0,64 & & & & & & 0,46 \\
\hline $\begin{array}{l}\text { 33. Quando alguém me pede para resolver um problema difícil, } \\
\text { encontro geralmente soluções criativas. }\end{array}$ & 0,63 & & & & & & 0,50 \\
\hline 62. Em comparação com os outros estudantes, a minha inteligência é: & 0,61 & & & & & & 0,44 \\
\hline $\begin{array}{l}\text { 2. Sou muitas vezes capaz de estabelecer relações entre coisas } \\
\text { aparentemente não relacionadas. }\end{array}$ & 0,61 & & & & & & 0,40 \\
\hline 20. Sou uma pessoa com muitas ideias. & 0,60 & & & & & & 0,47 \\
\hline 38. Possuo um vocabulário rico. & 0,58 & & & & & & 0,40 \\
\hline 57. Gosto de apresentar ideias não convencionais. & 0,56 & & & & & & 0,39 \\
\hline 15. Sou inovador(a). & 0,54 & & & & & & 0,46 \\
\hline 4. Sou rápido(a) a compreender as coisas. & 0,53 & & & & & & 0,38 \\
\hline 68. Sou considerado excecional ou com inteligência fora do comum. & 0,53 & & & & & & 0,33 \\
\hline $\begin{array}{l}\text { 47. Estou certo(a) de que consigo compreender a matéria mais difícil } \\
\text { apresentada nos apontamentos e leituras. }\end{array}$ & 0,51 & & & & & & 0,38 \\
\hline 36. Prefiro os problemas complexos aos simples. & 0,51 & & & & & & 0,33 \\
\hline 49. Tenho um pensamento flexível. & 0,50 & & & & & & 0,47 \\
\hline 7. Sou imaginativo(a). & 0,49 & & & & & & 0,38 \\
\hline 48. Utilizo palavras difíceis. & 0,46 & & & & & & 0,28 \\
\hline $\begin{array}{l}\text { 55. Tenho a certeza que consigo dominar as competências ensinadas } \\
\text { nas aulas. }\end{array}$ & 0,46 & & & & & & 0,45 \\
\hline 31 Sou multifacetado(a). & 0,42 & & & & & & 0,27 \\
\hline 9. Tenho uma cultura geral vasta. & 0,42 & & & & & & 0,26 \\
\hline 19. Tenho dificuldade em compreender ideias abstratas. & 0,35 & & & & & & 0,18 \\
\hline 50. Anseio por oportunidades para aprender e crescer. & & 0,64 & & & & & 0,56 \\
\hline 42. Reavalia as minhas suposições quando fico confuso. & & 0,64 & & & & & 0,48 \\
\hline 27. Paro e revejo a informação nova quando não é clara. & & 0,63 & & & & & 0,48 \\
\hline 46. Fico empolgado(a) quando aprendo alguma coisa nova. & & 0,60 & & & & & 0,48 \\
\hline 41. Quero aprender o mais possível. & & 0,59 & & & & & 0,50 \\
\hline 45. Desejo dominar completamente a matéria do meu estudo. & & 0,57 & & & & & 0,46 \\
\hline 10. Paro e releio quando fico confuso(a). & & 0,51 & & & & & 0,30 \\
\hline 51. Tenho interesses variados. & & 0,50 & & & & & 0,46 \\
\hline
\end{tabular}


Tabela 1 (continuação)

Estrutura Fatorial dos Itens do ICPADA

$$
\text { Itens }
$$

Fatores

22. É importante para mim compreender o conteúdo das aulas tão profundamente quanto possível.

63. Sou um(a) verdadeiro(a) aprendiz ao longo da vida.

\begin{tabular}{|c|c|c|c|c|c|c|}
\hline \multicolumn{7}{|c|}{ Fatores } \\
\hline I & II & III & IV & V & VI & $h^{2}$ \\
\hline & 0,48 & & & & & 0,36 \\
\hline & 0,47 & & & & & 0,41 \\
\hline & 0,47 & & & & & 0,41 \\
\hline & 0,39 & & & & & 0,24 \\
\hline & 0,38 & & & & & 0,21 \\
\hline
\end{tabular}

61. Gosto de ideias novas.

64. Vou imediatamente à biblioteca ou à internet se quero saber alguma coisa.

44. Sinto que praticamente qualquer tema pode ser altamente interessante desde que eu me envolva nele.

23. Desisto facilmente.

25. Termino o que começo apesar dos obstáculos que possam surgir.

11. Não termino o que começo.

0,67

54. Não desisto de uma tarefa antes de a ter terminado.

0,68

52. Sou trabalhador(a).

0,66

14. Não me distraio quando trabalho.

0,46

3. Demonstro iniciativa.

0,39

8. Consigo lidar facilmente com outras pessoas.

0,37

32. Os outros veem em mim uma pessoa sociável.

40. Sou bom(a) a trabalhar com outros.

12. Influencio de forma positiva a maneira como as outras pessoas se relacionam.

13. Aceito as ideias das outras pessoas.

30. É importante para mim fazer bem, comparando com os outros estudantes.

1. Leio uma grande variedade de livros.

16. Estou sempre a ler.

66. Não gosto de visitar museus.

\begin{tabular}{|c|c|c|c|c|c|c|}
\hline Valor-próprio & 14,98 & 4,18 & 2,97 & 2,5 & 1,94 & 1,77 \\
\hline \% Variância & 22,03 & 6,15 & 4,36 & 3,69 & 2,85 & 2,61 \\
\hline
\end{tabular}

Nesse estudo, o ICPADA aparece, assim, constituído por 52 itens organizados em seis fatores, tendo-se eliminado 16 itens dos 68 iniciais. Apesar de se manter o mesmo número de escalas do estudo de Scager et al. (2012), estas não têm uma correspondência linear tanto quanto ao número, ao tipo de itens e quanto ao domínio de significação. Nessa investigação, emergiram as dimensões: Cognitivo-Criativa, fator I (21 itens); Motivação e Estratégias de Aprendizagem, fator II (13 itens); Persistência, fator III (7 itens); Interação Social, fator IV (5 itens); Orientação para a
Excelência, fator V (3 itens); e Interesse Cultural, fator VI (3 itens).

Os resultados descritivos dos itens constituintes dos fatores são apresentados na Tabela 2. Verifica-se que, para todos os itens, obtiveram-se respostas dentro da amplitude possível (1 a 7 valores) e que, de forma geral, os valores médios se situam próximo do valor intermédio da escala (quatro valores) ou ligeiramente acima (cinco valores), situando-se o valor do desvio padrão próximo da unidade. De uma forma mais específica, verifica-se que, para o Fator I, a mediana de 12 itens 
é situada em quatro valores, para oito itens em cinco valores e em um item em seis valores. Todos os itens se apresentam correlacionados com o total da escala com nível moderado (entre 0,43 e 0,72), excetuando o item 19 em que o valor de correlação é mais baixo $(0,29)$. Para o Fator II, o valor da mediana é de cinco valores para seis itens, de seis valores para seis itens e de três valores para um item. Os itens correlacionam-se fortemente com o total do fator (valores entre 0,79 e 0,87 ). No Fator III, os valores da mediana são de seis valores para três itens, de cinco valores para outros três itens e de quatro valores para um item. Os valores de correlação dos itens com o total da escala são moderados (entre 0,41 e 0,71 ). Para o Fator IV, quatro itens apresentam um valor da mediana de cinco pontos e um item tem o valor de seis. Os valores de correlação dos itens com o total da escala são moderados (entre 0,35 e 0,63 ). Quanto ao fator V, constituído por três itens, cada um deles apresenta valores de mediana distintos: 3, 4 e 5 valores. Os índices de correlação desses itens com o total da escala são moderados (entre 0,69 a 0,76 ). Finalmente, para o Fator VI, dois itens apresentam uma mediana de três valores e num item a mediana é de seis valores. Os valores de correlação dos itens com o total da escala são moderados para dois itens $(0,63$ e 0,59$)$ e mais fracos $(0,28)$ para um item.

Uma análise complementar da constituição dos fatores é apresentada na Tabela 3. Pode-se constatar que os valores médios de resposta se apresentam entre os valores de 4 e $5\left(M_{\text {fatorI }}=4,49\right.$ e $D P=0,77 ; M_{\text {fatorII }}=5,22$ e $D P=0,69 ; \quad M_{\text {fatorIII }}=4,93$ e $D P=0,99 ; M_{\text {fatorl }}=5,06$ e $\left.D P=0,94 ; M_{\text {fator } V}=4,01 \mathrm{e} D P=1,45\right)$, sendo que, para o Fator VI, os valores médios são um pouco mais baixos $\left(M_{\text {fatorlI }}=3,89\right.$ e $\left.D P=1,32\right)$. O índice de fidelidade (alfa de Cronbach) é adequado para os fatores I, II, III e V, e razoável para os Fatores IV e VI.

Tabela 2

Estatística Descritiva dos Itens do ICPADA

\begin{tabular}{|c|c|c|c|c|c|}
\hline & $\mathrm{N}$ & M & Md & $\mathrm{DP}$ & ritc \\
\hline \multicolumn{6}{|l|}{ Fator I } \\
\hline 39. Sou capaz de compreender novas ideias com facilidade. & 1360 & 4,90 & 5,00 & 1,14 & 0,72 \\
\hline $\begin{array}{l}\text { 37. Sou muitas vezes capaz de perceber o panorama geral, enquanto os outros } \\
\text { não o conseguem fazer. }\end{array}$ & 1356 & 4,19 & 4,00 & 1,34 & 0,64 \\
\hline $\begin{array}{l}\text { 21. Tenho uma capacidade para descobrir o potencial de ideias que os outros } \\
\text { geralmente não conseguem ver. }\end{array}$ & 1357 & 4,28 & 4,00 & 1,29 & 0,63 \\
\hline $\begin{array}{l}\text { 33. Quando alguém me pede para resolver um problema difícil, encontro ge- } \\
\text { ralmente soluções criativas. }\end{array}$ & 1362 & 4,43 & 4,00 & 1,24 & 0,66 \\
\hline 62. Em comparação com os outros estudantes, a minha inteligência é: & 1309 & 4,49 & 4,00 & 0,97 & 0,57 \\
\hline $\begin{array}{l}\text { 2. Sou muitas vezes capaz de estabelecer relações entre coisas aparentemen- } \\
\text { te não relacionadas. }\end{array}$ & 1358 & 4,33 & 4,00 & 1,28 & 0,57 \\
\hline 20. Sou uma pessoa com muitas ideias. & 1356 & 4,87 & 5,00 & 1,26 & 0,62 \\
\hline 38. Possuo um vocabulário rico. & 1364 & 4,36 & 4,00 & 1,31 & 0,60 \\
\hline 57. Gosto de apresentar ideias não convencionais. & 1364 & 4,63 & 5,00 & 1,43 & 0,55 \\
\hline 15. Sou inovador(a). & 1361 & 4,50 & 4,00 & 1,17 & 0,59 \\
\hline 4. Sou rápido(a) a compreender as coisas. & 1362 & 4,88 & 5,00 & 1,10 & 0,54 \\
\hline 68. Sou considerado excecional ou com inteligência fora do comum. & 1354 & 3,36 & 4,00 & 1,49 & 0,43 \\
\hline $\begin{array}{l}\text { 47. Estou certo(a) de que consigo compreender a matéria mais difícil apresen- } \\
\text { tada nos apontamentos e leituras. }\end{array}$ & 1355 & 4,11 & 4,00 & 1,32 & 0,55 \\
\hline 36. Prefiro os problemas complexos aos simples. & 1360 & 4,14 & 4,00 & 1,52 & 0,51 \\
\hline 49. Tenho um pensamento flexível. & 1359 & 5,10 & 5,00 & 1,21 & 0,57 \\
\hline 7. Sou imaginativo(a). & 1362 & 5,38 & 6,00 & 1,30 & 0,52 \\
\hline 48. Utilizo palavras difíceis. & 1363 & 3,89 & 4,00 & 1,40 & 0,51 \\
\hline $\begin{array}{l}\text { 55. Tenho a certeza que consigo dominar as competências ensinadas nas } \\
\text { aulas. }\end{array}$ & 1363 & 4,80 & 5,00 & 1,22 & 0,53 \\
\hline 31. Sou multifacetado(a). & 1356 & 4,61 & 5,00 & 1,48 & 0,45 \\
\hline
\end{tabular}


Tabela 2 (continuação)

Estatística Descritiva dos Itens do ICPADA

\begin{tabular}{|c|c|c|c|c|c|}
\hline & $N$ & $M$ & Md & DP & ritc \\
\hline 9. Tenho uma cultura geral vasta. & 1361 & 4,50 & 4,00 & 1,27 & 0,44 \\
\hline 19. Tenho dificuldade em compreender ideias abstratas. & 1362 & 4,68 & 5,00 & 1,34 & 0,29 \\
\hline \multicolumn{6}{|l|}{ Fator II } \\
\hline 50. Anseio por oportunidades para aprender e crescer. & 1360 & 5,58 & 6,00 & 1,17 & 0,79 \\
\hline 42. Reavalia as minhas suposições quando fico confuso. & 1362 & 5,36 & 5,00 & 1,16 & 0,80 \\
\hline 27. Paro e revejo a informação nova quando não é clara. & 1360 & 5,50 & 6,00 & 1,14 & 0,80 \\
\hline 46. Fico empolgado(a) quando aprendo alguma coisa nova. & 1356 & 5,36 & 5,00 & 1,24 & 0,79 \\
\hline 41. Quero aprender o mais possível. & 1362 & 5,91 & 6,00 & 1,14 & 0,80 \\
\hline 45. Desejo dominar completamente a matéria do meu estudo. & 1364 & 5,26 & 5,00 & 1,35 & 0,80 \\
\hline 10. Paro e releio quando fico confuso(a). & 1358 & 5,89 & 6,00 & 1,12 & 0,81 \\
\hline 51. Tenho interesses variados. & 1362 & 5,84 & 6,00 & 1,14 & 0,80 \\
\hline $\begin{array}{l}\text { 22. É importante para mim compreender o conteúdo das aulas tão profunda- } \\
\text { mente quanto possível. }\end{array}$ & 1363 & 5,17 & 5,00 & 1,41 & 0,80 \\
\hline 63. Sou um(a) verdadeiro(a) aprendiz ao longo da vida. & 1360 & 2,64 & 3,00 & 1,27 & 0,87 \\
\hline 61. Gosto de ideias novas. & 1347 & 5,61 & 6,00 & 1,16 & 0,80 \\
\hline 64. Vou imediatamente à biblioteca ou à internet se quero saber alguma coisa. & 1362 & 5,16 & 5,00 & 1,53 & 0,81 \\
\hline $\begin{array}{l}\text { 44. Sinto que praticamente qualquer tema pode ser altamente interessante } \\
\text { desde que eu me envolva nele. }\end{array}$ & 1356 & 4,56 & 5,00 & 1,60 & 0,81 \\
\hline \multicolumn{6}{|l|}{ Fator III } \\
\hline 23. Desisto facilmente. & 1364 & 5,44 & 6,00 & 1,49 & 0,61 \\
\hline 25. Termino o que começo apesar dos obstáculos que possam surgir. & 1363 & 5,04 & 5,00 & 1,36 & 0,71 \\
\hline 11. Não termino o que começo. & 1364 & 5,24 & 6,00 & 1,56 & 0,54 \\
\hline 54. Não desisto de uma tarefa antes de a ter terminado. & 1362 & 5,01 & 5,00 & 1,47 & 0,70 \\
\hline 52. Sou trabalhador(a). & 1364 & 5,37 & 6,00 & 1,44 & 0,56 \\
\hline 14. Não me distraio quando trabalho. & 1364 & 3,72 & 4,00 & 1,40 & 0,41 \\
\hline 3. Demonstro iniciativa. & 1362 & 4,66 & 5,00 & 1,23 & 0,47 \\
\hline \multicolumn{6}{|l|}{ Fator IV } \\
\hline 8. Consigo lidar facilmente com outras pessoas. & 1363 & 5,23 & 5,00 & 1,40 & 0,63 \\
\hline 32. Os outros veem em mim uma pessoa sociável. & 1358 & 4,70 & 5,00 & 1,53 & 0,59 \\
\hline 40. Sou bom(a) a trabalhar com outros. & 1359 & 5,06 & 5,00 & 1,33 & 0,59 \\
\hline 12. Influencio de forma positiva a maneira como as outras pessoas se relacionam. & 1358 & 4,80 & 5,00 & 1,14 & 0,52 \\
\hline 13. Aceito as ideias das outras pessoas. & 1364 & 5,52 & 6,00 & 1,10 & 0,35 \\
\hline \multicolumn{6}{|l|}{ Fator $\mathrm{V}$} \\
\hline $\begin{array}{l}\text { 35. O meu objetivo é obter melhores classificações do que a maior parte dos } \\
\text { estudantes. }\end{array}$ & 1361 & 3,53 & 3,00 & 1,73 & 0,71 \\
\hline 26. É importante para mim fazer melhor que os outros estudantes. & 1363 & 3,98 & 4,00 & 1,65 & 0,76 \\
\hline 30. É importante para mim fazer bem, comparando com os outros estudantes. & 1360 & 4,51 & 5,00 & 1,62 & 0,69 \\
\hline \multicolumn{6}{|l|}{ Fator VI } \\
\hline 1. Leio uma grande variedade de livros. & 1365 & 3,24 & 3,00 & 1,67 & 0,63 \\
\hline 16. Estou sempre a ler. & 1362 & 3,25 & 3,00 & 1,61 & 0,59 \\
\hline 66. Não gosto de visitar museus. & 1363 & 5,18 & 6,00 & 1,81 & 0,28 \\
\hline
\end{tabular}


Tabela 3

Estatística Descritiva dos Fatores e Respetivo Alfa de Cronbach

\begin{tabular}{|c|c|c|c|c|c|c|}
\hline Fator & $N$ & $M$ & $D P$ & Mín. & Máx. & $\alpha$ \\
\hline I. Cognitivo-criativo & 1252 & 4,49 & 0,77 & 1,14 & 6,90 & 0,91 \\
\hline II. Motivação e Estratégias de Aprendizagem & 1309 & 5,22 & 0,69 & 2,65 & 5,90 & 0,80 \\
\hline III. Persistência & 1356 & 4,93 & 0,99 & 1,14 & 7,00 & 0,83 \\
\hline IV. Interação Social & 1348 & 5,06 & 0,94 & 1,60 & 7,00 & 0,76 \\
\hline V. Procura de Excelência & 1356 & 4,01 & 1,45 & 1,00 & 7,00 & 0,85 \\
\hline VI. Interesse Cultural & 1360 & 3,89 & 1,32 & 1,00 & 7,00 & 0,67 \\
\hline
\end{tabular}

\section{Discussão}

Os resultados revelam-se promissores face ao objetivo de contribuir para um conhecimento mais aprofundado dos alunos de mérito escolar no ensino superior, por meio da validação de um instrumento para avaliar características psicológicas associadas ao rendimento acadêmico em estudantes portugueses. De forma mais específica, o ICPADA, construído a partir de um modelo teórico que preconiza a produção excelente em função de fatores motivacionais, criativos e cognitivos, numa interação entre fatores ambientais e de personalidade (Renzulli, 2005), apresenta caraterísticas psicométricas válidas que permitem, em contexto de avaliação, obter informação sobre dimensões psicológicas dos alunos.

$\mathrm{Na}$ versão portuguesa, a análise fatorial revela um questionário multidimensional, composto por seis fatores (Cognitivo-Criativo, Motivação e Estratégias de Aprendizagem, Persistência, Interação Social, Orientação para a Excelência e Interesse Cultural) com um número diferenciado de itens. No entanto, os seis fatores encontrados não correspondem linearmente aos seis fatores (Inteligência, Pensamento Criativo, Abertura à Experiência, Desejo de Aprender, Orientação para a Excelência e Persistência) do questionário utilizado por Scager et al. (2012). Também o número de itens a reter no questionário final português é superior (52 itens) à versão final holandesa (31 itens).

Os resultados revelam que os alunos, de forma geral, encontram-se motivados com o processo de aprendizagem na medida em que as escalas com valores médios mais elevados correspondem, na versão portuguesa, à escala Motivação e Estratégias de Aprendizagem e, na versão holandesa, à escala Desejo de Aprender (Scager et al., 2012). Também se encontram equiparadas as escalas com valores médios mais baixos, ou seja, na versão portuguesa estes encontram-se nas escalas Interesse Cultural e Orientação para a Excelência, sendo que, na versão holandesa, registam-se na escala Orientação para a Excelência (Scager et al., 2012).

No ICPADA, o Fator I, denominado CognitivoCriativo, agrupa 21 itens sendo que, na escala original, as duas dimensões aparecem separadas em escalas distintas: Inteligência e Pensamento Criativo (Scager et al., 2012). $\mathrm{Na}$ versão portuguesa, além de se incluírem itens nesse fator que não constavam na escala Inteligência nem na escala Pensamento Criativo ou mesmo em outra escala, incluem-se itens que correspondiam à escala Abertura à Experiência ("Sou uma pessoa com muitas ideias", "Sou inovador(a)" e "Sou imaginativo(a)"). Parece que esses dados podem traduzir que os dois conceitos estão agrupados ao contribuírem para a realização excelente (Almeida \& Wechsler, 2015). Aliás, do ponto de vista mais teórico, Renzulli (2005) pressupõe a interação entre diferentes variáveis a propiciar o desempenho excelente quando contempla a necessidade de interação da criatividade com a alta habilidade e o compromisso com a tarefa, quer quando avança com a reformulação desse modelo e contempla a interação dos fatores co-cognitivos (e. g., componentes como a energia mental/física, caracterizada pelo carisma e curiosidade). Também do ponto de vista empírico, regista-se a presença de diversas características a contribuir para o sucesso dos alunos (Scager et al., 2012), sendo que a curiosidade e a abertura à experiência surgem como traços de personalidade associados frequentemente à pessoa criativa (Starko, 2010).

O Fator II, Motivação e Estratégias de Aprendizagem, contem 13 itens, dos quais cinco correspondem aos da escala original Desejo de Aprender, revelando a versão portuguesa consistência interna dos itens com um alfa de Cronbach bastante satisfatório (0.80). Nessa dimensão do ICPADA, constata-se itens que, por um lado, apelam à predisposição mental face ao estudo (e. g., "Quero aprender o mais possível") e, por outro, itens que apelam ao comportamento face ao estudo (e. g., "Paro e revejo a informação nova quando não é clara"). No entanto, essa diferenciação não se manifestou na análise fatorial. Essa não diferenciação dos itens talvez traduza que, à medida que se avança na escolaridade, as metas acadêmicas vão sendo construídas a partir de objetivos ora centrados na aprendizagem ora centrados nos resultados (Miranda \& Almeida, 2014), sendo que a motivação e as estratégias de aprendizagem se revelam importantes na concretização dos objetivos de sucesso acadêmico (Monteiro et al., 2014). 
O Fator III, Persistência, agrupa sete itens, sendo que quatro deles coincidem com os itens da escala original. Um dos itens que emerge na escala portuguesa ("Demonstro iniciativa"), ainda que o seu nível de saturação seja o mais baixo de todos os itens da escala $(0,37)$, desencadeou algum questionamento. Supõe-se que essa associação à Persistência possa ser explicada por uma interpretação dos alunos face à iniciativa no sentido de se persistir no alcance de objetivos e de lutar pela sua concretização, de não se acomodar e esperar que a situação seja resolvida por outra pessoa. Na literatura, esse aspeto, lido, por exemplo, como compromisso com a tarefa (Renzulli, 2005) ou como a motivação para o investimento necessário ao desenvolvimento de competências e prática deliberada (Heller, Perleth, \& Lim, 2005), revela-se fundamental no alcance de resultados excecionais.

A Interação Social, Fator IV, e o Interesse Cultural, Fator VI, aparecem apenas no ICPADA. O primeiro é constituído por cinco itens (alfa de Cronbach de 0,76), e o segundo por três itens (alfa de Cronbach de 0,67). Os valores de consistência interna parecem satisfatórios, sendo que, em estudos futuros, poder-se-ia procurar a melhoria desses valores sobretudo para a dimensão Interesse Cultural. A presença desses fatores traduz, mais uma vez, a relevância de fatores não cognitivos na explicação do desempenho acadêmico, sobretudo no caso do sucesso acadêmico (Friedman-Nimz \& Skyba, 2009; Komarraju et al., 2011).

Finalmente, a Orientação para a Excelência, Fator $\mathrm{V}$, é constituído por três itens (alfa de Cronbach de $0,85)$, que correspondem aos da escala original. Essa dimensão, considerando a revisão da literatura, permite perceber a sua presença ao traduzir objetivos de sucesso acadêmico e metas de aprendizagem dos alunos (Miranda \& Almeida, 2014).

No entanto, limitações podem ser apontadas a este estudo. Usa-se um questionário de autorrelato, carecendo, portanto, de informação contrastante. Nesse sentido, para estudos futuros, sugere-se a introdução de medidas de desempenho para aferir a validade de critério. Também a validade de construto poderá levantar questionamentos devido à variedade de variáveis quando se estuda o desempenho excecional e à dificuldade de formas de avaliação concreta delas (Renzulli, 2005; Rinn, 2005). Poderá ser questionada ainda a tentativa de agrupar em um só instrumento de avaliação essa diversidade de variáveis, podendo aparecer como uma medida redutora da complexidade do fenômeno das habilidades acadêmicas, sendo que outros autores também alertam para a dificuldade de cruzar informação oriunda de diferentes e múltiplas fontes (Lohman, 2009). Apesar dessas limitações, os resultados sobre o ICPADA constituem um contributo à avaliação psicológica, traduzindo a construção de um inventário que permite diferenciar e caracterizar alunos, permitindo obter informação sobre várias dimensões, destacando-se ainda o seu carácter inovador dada a não existência, até então, de um instrumento que permita avaliar essa dimensões. A utilização do ICPADA (Antunes et al., 2015), tal como já tinha acontecido na versão holandesa (Scager et al., 2012), já revelou dados pertinentes para a caracterização de grupos diferentes de alunos, permitindo perceber que os alunos de mérito escolar se percepcionam, em algumas dimensões e em função da área de conhecimento, de forma diferenciada dos restantes colegas.

\section{Referências}

Achterberg, C. (2005). What is an honors student? Journal of the National Collegiate Honors Council, 6(1), 75-81. Disponível em http:// digitalcommons.unl.edu/nchcjournal/170

Almeida, L. S., \& Wechsler, S. M. (2015). Excelência profissional: a convergência necessária de variáveis psicológicas. Estudos de Psicologia (Campinas), 32(4), 767-775. doi: 10.1590/0103-166X2015000400019

Antunes, A. P., \& Almeida, L. S. (2010). Alunos com altas habilidades: Valor preditivo dos critérios de identificação. Em L. S. Almeida, B. D. Silva, \& S. Caires (Eds.), Actas do I Seminário Internacional Contributos da Psicologia em Contextos Educativos (pp. 365-376). Braga: CIEdUniversidade do Minho. Recuperado de http://hdl.handle.net/1822/11407

Antunes, A. P., \& Morais, M. F. (2015). Alunos excelentes, alunos promissores? A questão dos alunos de mérito académico no ensino superior. Revista Talento, Inteligencia y Creatividad, 1(2), 3-23. Recuperado de http://www.talincrea.cucs.udg.mx/sites/default/files/ Articulo\%20Alunos\%20excelentes....pdf

Antunes, A. P., Morais, M. F., \& Martins, F. (2015). Rendimento académico elevado e caraterísticas psicológicas associadas: Diferenciação dos alunos de mérito académico no ensino superior. Em A. M. Araújo, A. A. Martins, A. F. Alves, A. O. Amaral, \& L. S. Almeida (Eds.), Atas do III Seminário Internacional Cognição, Aprendizagem e Desempenho (pp. 122-131). Braga: Universidade do Minho.

Friedman-Nimz, R., \& Skyba, O. (2009). Personality qualities that help or hinder gifted and talented individuals. Em L. V. Shavinina (Ed.), International handbook on giftedness (pp. 421-435). New York, NY: Springer.

Gunther, Z. C. (2015). Reconhecimento, identificação e desenvolvimento de talentos. Revista Talento, Inteligencia y Creatividad, 2(1), 1-17. Recuperado de http://www.talincrea.cucs.udg.mx/articulo/reconhecimento-identificacao-e-desenvolvimento-de-talentos

Heller, K. A., Perleth, C., \& Lim, T. K. (2005). The Munich model of giftedness designed to identify and promote gifted students. Em R. J. Sternberg, \& J. Davidson (Eds.), Conceptions of giftedness (2nd ed., pp. 147-170). New York: Cambridge University Press.

Kim, K. H. (2009). The two pioneers of research on creative giftedness: Calvin W. Taylor and E. Paul Torrance. Em L. V. Shavinina (Ed.), International handbook on giftedness (pp. 571-583). New York, NY: Springer. 
Komarraju, M., Karau, S. J., Schmeck, R. R., \& Avdic, A. (2011). The Big Five personality traits, learning styles, and academic achievement. Personality and Individual Differences, 51(4), 472-477. doi: 10.1016/j.paid.2011.04.019

Lohman, D. F. (2009). Identifying academically talented students: Some general principles, two specific procedures. Em L. V. Shavinina (Ed.), International handbook on giftedness (pp. 971-997). New York, NY: Springer.

McLaughlin, J. (2015). Working with gifted college and university students: Journals, organizations, and scholarships. The Reference Librarian, 56(1), 42-51. doi: 10.1080/02763877.2014.968824

Miranda, L. C., \& Almeida, L. S. (2014). Inventário de metas académicas (IMA). Em L. Almeida, M. R. Simões, \& M. Gonçalves (2014). Instrumentos e Contextos de Avaliação Psicológica (Vol. II, pp. 135-151). Lisboa: Almedina.

Monteiro, S., Almeida, L. S., Rosa, M. V., \& Cruz, J. F. (2014). Be(com)ing an excellent student: A qualitative study with engineering undergraduates. High Ability Studies, 25(2), 169-186. doi: 10.1080/13598139.2014.966066

Morais, M. F. (2013). Creativity: Challenges to a key-concept for the 21th century. Em A. Antonietti, B. Colombo, \& D. Memmert (Eds.), Psychology of creativity: Advances in theory, research and application (pp. 3-19). New York: Nova Publishers.

Renzulli, J. S. (2005). The three ring conception of giftedness: A developmental model for creative productivity. Em R. J. Sternberg, \& J. Davidson (Eds.), Conceptions of giftedness (2nd ed., pp. 246-279). Cambridge: Cambridge University Press.

Rinn, A. N. (2005). Trends among honors college students: An analysis by year in school. The Journal of Secondary Gifted Education, 16(4), 1571-67. doi: 10.4219/jsge-2005-479

Scager, K., Akkerman, S. F., Keesen, F., Mainhard, M. T., Pilot, A., \& Wubbels, T. (2012). Do honors students have more potential for excellence in their professional lives? Higher Education, 64(1), 19-39. doi: 10.1007/s10734-011-9478-z

Starko, A. J. (2010). Creativity in the classroom: Schools of curious delight. New York: Routledge.

\section{Sobre as autoras}

Ana Pereira Antunes é Doutora em Psicologia, área de especialização em Psicologia da Educação, pela Universidade do Minho; é Professora Auxiliar na Universidade da Madeira.

Maria de Fátima Morais é Doutora em Psicologia, área de especialização em Psicologia da Educação, pela Universidade do Minho; é Professora Auxiliar nesta mesma Universidade.

Fernanda Martins é Doutora em Psicologia, área de especialização em Psicologia da Educação, pela Universidade do Minho; é Professora Auxiliar na Faculdade de Letras da Universidade do Porto. 